\title{
A NEGAÇÃO DO DIREITO À DIFERENÇA NO COTIDIANO ESCOLAR ${ }^{1}$
}

\author{
Maria Teresa Esteban*
}

Recebido: 5 mar. 2014

Aprovado: 30 maio 2014

* Universidade Federal Fluminense. Niterói, RJ, Brasil. E-mail: mtesteban@uol.com.br

Resumo: Este artigo se propõe a contribuir com o debate sobre a qualidade da educação no Brasil, colocando em diálogo os procedimentos de avaliação instaurados, com ênfase na avaliação externa baseada em provas estandardizadas, e os processos de democratização da escola pública. Questiona o lugar que estudantes e professores/as ocupam na avaliação externa e evidencia outros percursos para a avaliação tomando como referência as questões postas pelo cotidiano escolar. Articula a reflexão considerando a necessidade de discutir a qualidade da educação para as classes populares, em consonância, também, com o movimento docente.

Palavras-chave: Avaliação. Cotidiano escolar. Heterogeneidade.

\section{THE DENIAL OF THE RIGHT TO BE DIFFERENT IN THE LIFE DAYLY OF SCHOOLS}

Abstract: This article aims to contribute with the debate on the quality of education in Brazil, by discussing the evaluation procedures which are in place, with emphasis on external evaluation based on standardized tests, and the democratization processes in the public school. It questions the place occupied by students and teachers in external evaluation and highlights other possible trajectories for evaluation, taking as references issues of daily life in school. It considers the necessity to discuss educational quality for the popular classes in consonance with the teachers' movement.

Key words: Evaluation. Daily school life. Heterogeneity.

1 Este artigo tem como referência minha participação na Mesa Redonda Avaliação, diferença e qualidade, realizada no VII Congresso Internacional de Educação da Universidade do Vale do Rio dos Sinos III Congresso Internacional de Avaliação. O texto se relaciona a pesquisa que desenvolvo com apoio do CNPq. 
Escrevo este artigo em um momento de grande efervescência para o movimento social e em especial para o movimento de professores no Rio de Janeiro. Está em curso uma longa greve, com forte mobilização docente e grande apoio da população, em torno de uma pauta de reivindicações que, para além das questões salariais, traz questões que explicitam uma disputa em relação ao conceito de qualidade e dos processos para alcançá-la².

Portanto, nós, professores e professoras, consideramos indiscutível a necessidade de que a escola pública adquira uma nova qualidade. Tal reconhecimento, em grande parte, se vincula à presença massiva das classes populares na escola pública, que também vem ampliando seu tempo de escolarização e alcançando, de modo crescente, níveis de ensino ainda pouco acessíveis a determinados segmentos sociais.

Esse processo traz novas exigências e potencialidades para o cotidiano escolar e para as políticas públicas. Reinscreve o debate sobre qualidade da educação e, nela, da escolarização, como parte da qualidade de vida, ao aproximá-lo da histórica negação de direitos fundamentais às classes populares. A ausência de uma educação de qualidade é parte indissociável do processo de subalternização das classes populares, enquanto a presença desses sujeitos na escola resulta de sua árdua e histórica luta contra a colonialidade - que destitui a validade de suas experiências - e pelos seus direitos, dentre os quais a escola se destaca. Porém, as possibilidades que a escolarização oferece não são descoladas dos limites que a vida social impõe. Não há determinação, mas os vínculos não podem ser ignorados:

A taxa de escolarização líquida, analisada pelos quintos do rendimento
mensal familiar per capita, revela fortes desigualdades entre os mais
pobres e os mais ricos: no primeiro quinto (os $20 \%$ mais pobres),
somente $32,0 \%$ dos adolescentes de 15 a 17 anos de idade estavam
no ensino médio, enquanto no último quinto ( $20 \%$ mais ricos), essa
oportunidade atingia quase $78 \%$ deste grupo, revelando que a renda
familiar exerce grande influência na adequação idade/série frequen-
tada (IBGE, 2010, p. 48).

Considerando a força das relações entre a dimensão econômica e as possibilidades de permanência na escola, devemos observar também que muitos estudantes se mantêm na escola com um percurso pouco exitoso, o que indica

2 O SEPE (Sindicado Estadual dos Profissionais da Educação do Rio de Janeiro) em seu boletim divulgou a seguinte pauta de reivindicações: Reajuste de 19\%; Plano de Carreira unificado; 1/3 da carga horária para Planejamento; Melhoria das condições de trabalho nas escolas e creches e Espaço do Desenvolvimento Infantil (Edis); Fim da Meritocracia. 
a existência de outras relações, talvez menos evidentes, entrelaçadas ao que imediatamente se apresenta como renda familiar. Igualmente relevantes para a reflexão, os dados obtidos pela PNAD 2012 (IBGE, 2013) mostram que 19,6\% dos jovens de 15 a 29 anos não trabalham nem estudam, 45,2\% somente trabalham, $13,6 \%$ trabalham e estudam e 21,6\% apenas estudam. Esse conjunto de questões me leva a interrogar, mais uma vez, quanto dos resultados insatisfatórios e do distanciamento do jovem (ou da criança, que não se refletem nos dados expostos) expressa uma inadequação da escola, em seu conteúdo e forma, às efetivas demandas, intenções e potências das classes populares.

As complexas relações entre desigualdade socioeconômica e desigualdade escolar evidenciam a insuficiência das soluções técnicas e expõem a necessidade de transformações mais profundas. O movimento popular não vem lutando por uma escola qualquer. Nesse sentido, o acesso é condição necessária, embora não suficiente, para que a escola se configure como parte desse processo e se mostre significativa para o fortalecimento individual e coletivo na luta pelas transformações ainda indispensáveis. Nosso compromisso está, fundamentalmente, com a democratização do acesso ao conhecimento, sem o que não se pode pensar na consolidação de uma sociedade democrática.

Essas questões alinhavam este artigo, cuja intenção é contribuir com o debate sobre a qualidade da educação no Brasil, colocando em diálogo os procedimentos de avaliação instaurados, com ênfase na avaliação externa baseada em provas estandardizadas, e os processos de democratização da escola pública.

\section{ENQUADRAMENTO, DESLOCAMENTOS E INVISIBILIDADE}

Recorro, uma vez mais, a uma imagem, na próxima página, que sempre me causa impacto.

Ao ver a Ficha de Correção da Provinha Brasil ${ }^{3}$, me pergunto que conhecimento sobre os estudantes se pretende produzir com a realização de um exame ${ }^{4}$ cujos resultados se podem expressar desse modo. Questiono a qualidade pretendida e a proposta pedagógica anunciada em um procedimento tão redutor.

Muitas são minhas preocupações em relação ao que vem sendo proposto, pelas políticas públicas, como um sistema de avaliação externa da Educação no

3 A Ficha de Correção da Provinha Brasil é um dos documentos que compõem o Kit Teste, da Provinha Brasil. Segundo o Guia de Correção: "A correção e a interpretação das respostas dos alunos às 20 questões de múltipla escolha serão feitas mediante o registro dos seus acertos. Para facilitar o processo de correção, encaminhamos uma ficha anexa. Dessa forma, o primeiro passo a ser adotado para proceder à correção do teste é ter em mãos cópias das fichas para marcação das respostas dos alunos.” (INEP, 2011, p.12).

4 Para a distinção entre exame e avaliação, ver Díaz Barriga (1999). 
Brasil que pretende aferir a qualidade existente e indicar a que se deve alcançar. Considerando as características do sistema em vigor, ancorado na realização de provas estandardizadas e na produção de rankings, destaco aqui dois aspectos - a uniformização e a simplificação - para refletir sobre o projeto de qualidade em que se sustentam e sobre a (im)possibilidade de a escola pública ter esse processo de avaliação como referência para suas práticas pedagógicas cotidianas.

Figura 1 - Ficha de Correção da Provinha Brasil

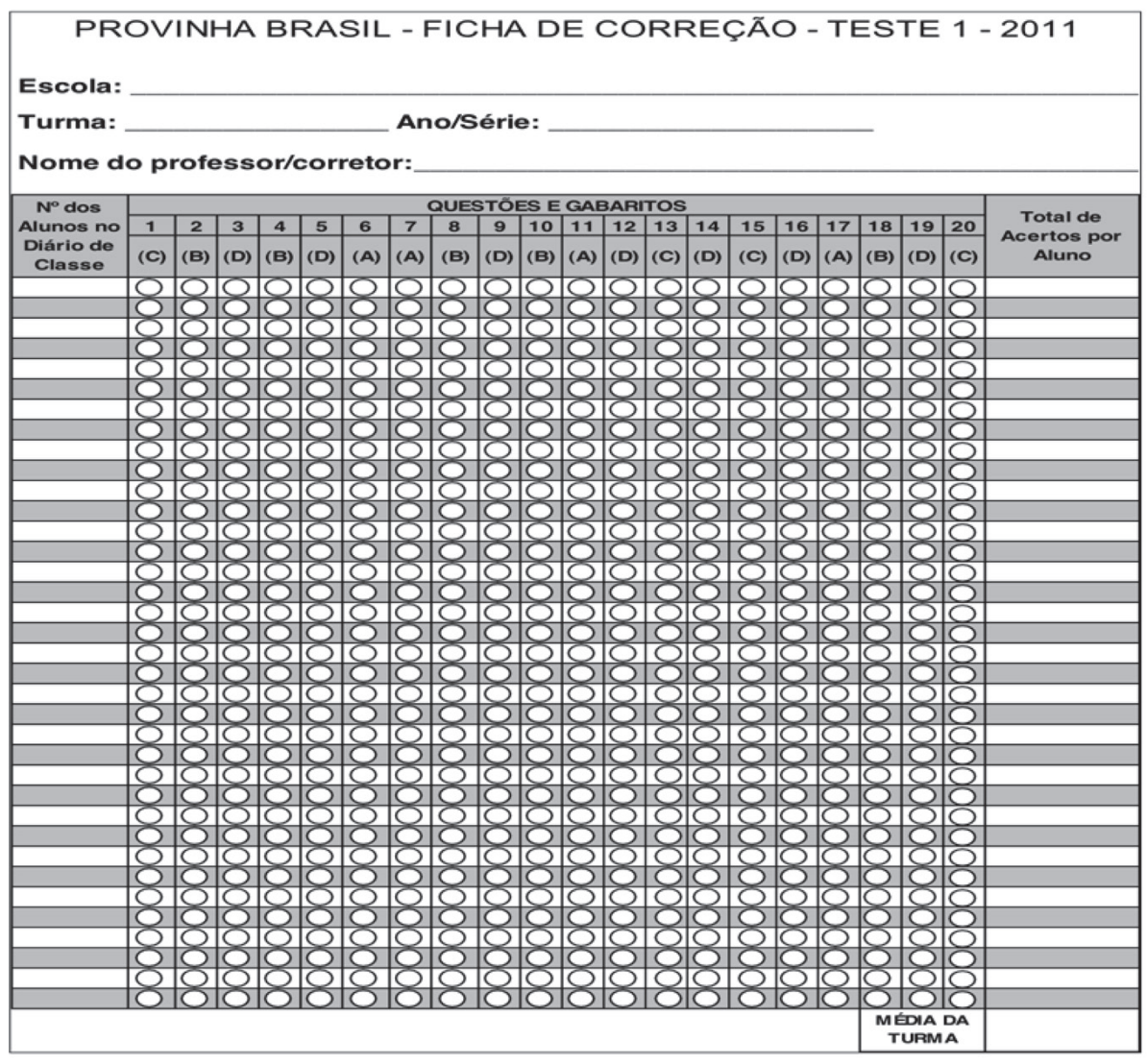

Para dar início à reflexão a que me proponho, parto de uma formulação de Regina Leite Garcia: "A Educação é monocultural, enquanto a sociedade brasileira é pluricultural". Tal enunciado evidencia o descompasso entre o projeto educacional e a dinâmica social. Este projeto se articula às perspectivas de uma parcela da sociedade, que por ser hegemônica apresenta sua visão de mundo 
como a única legítima, embora efetivamente não corresponda aos interesses de todos e coloque à margem predominantemente os estudantes das classes populares. Essa busca da educação sob uma ótica monocultural, constituída em relações de colonialidade que alimentam os processos de subalternização (MIGNOLO, 2003), tem norteado a visão de qualidade presente nas atuais políticas públicas no âmbito da avaliação educacional.

Nesse projeto se configuram modelos de escolarização que valorizam a homogeneidade de processos, percursos e resultados, o que não exclui a possibilidade de pequenos e superficiais ajustes a determinadas características dos contextos em que se realizam. Os conteúdos escolares, os materiais pedagógicos, os procedimentos didáticos e os resultados esperados devem ser uniformes, de modo a oferecer a e exigir de todos o mesmo. A escola, assim constituída, se alia ao discurso que associa o democrático à garantia da igualdade de oportunidades e não à igualdade de direitos.

Considerando que além de pluricultural a sociedade brasileira é extremamente desigual, cabe indagar: as escolas podem garantir a uniformidade requerida, em contextos com enormes disparidades socioeconômicas e grandes diferenças culturais? Quanto dessa uniformização é parte de um processo de desqualificação e destruição de culturas que diferem da hegemônica? A escola de qualidade deve cumprir esse papel?

Não trago essas perguntas com a intenção de respondê-las, mas por entender que guardam problemas nos quais dialogam avaliação, qualidade e projeto educacional. A avaliação educacional - seja da aprendizagem ou do sistema - tem, indiscutivelmente, importante papel na articulação de um projeto de educação de melhor qualidade do que o atual. Nossa educação ainda é altamente excludente e guarda mecanismos que fazem renascer, sob novas configurações, o fracasso das classes populares, ainda que se reduzam os níveis de evasão e de repetência e se ampliem o acesso à escola e o tempo médio de escolarização. O projeto de educação permite, e muitas vezes estimula, a recomposição dos processos de exclusão ao produzir dinâmicas cujos resultados não garantem a efetiva apropriação dos conhecimentos pelas classes populares. A experiência no cotidiano escolar traz muitas evidências do descompasso entre o tempo de escolarização dos estudantes e sua aprendizagens e dados apresentados tanto pela PNAD (anteriormente referidos) quanto pelo INEP $^{5}$ corroboram essa percepção e explicitam a desigualdade presente no sistema educacional.

5 A esse respeito, consultar os indicadores educacionais relativos a distorção idade-série e observar, especialmente, as diferenças entre os resultados obtidos na zona rural e na zona urbana e entre a rede pública e a rede privada. Disponível em: $<$ http://portal.inep.gov.br/web/portal-ideb/portal-ideb $>$. Acesso: 12 fev. 2014. 
Nesse sentido, é preciso considerar os dados socioeconômicos e simultaneamente buscar uma aproximação com o cotidiano escolar, para encontrar os atos que, em articulação com os processos extraescolares de exclusão, dia a dia vão se tornando obstáculos para que a aprendizagem se dê e transformam a escolarização numa experiência pouco significativa para um grande número de estudantes. Mesmo para os que vão à escola, não são reprovados e nela permanecem por longos anos.

A Ficha de Correção da Provinha Brasil, anteriormente apresentada (Fig. 01), traz elementos interessantes para um aprofundamento dessa discussão, pensando nos sujeitos envolvidos no processo aprendizagemensino que tal documento pretende sintetizar. Um primeiro aspecto que se evidencia é a invisibilidade do sujeito, que se apresenta por meio de um número associado à informação sobre a quantidade de acertos verificados na prova objetiva, com 20 questões, realizada.

\section{DE QUEM SE FALA?}

Certamente, não de uma criança, no período inicial da escolarização obrigatória, começando o longo e complexo processo de aprendizagem sistemática da língua escrita. Uma criança que, frequentemente, teria na escola um dos principais lugares para sua inserção na cultura escrita. Uma criança que em sua interação com o mundo se depara com a escrita, de muitos modos, em vários lugares, com diferentes sentidos, e na escola encontraria a possibilidade de fazer aprendizagens sobre a escrita e se apropriar de modo crescente desse conhecimento, em consonância com a ideia, tantas vezes repetida, de Freire: a leitura do mundo precede a leitura da palavra. Uma criança que confrontando suas múltiplas experiências com a escrita, inclusive as escolares, cria hipóteses, faz tentativas, consolida aprendizagens, reconhece seus saberes, encontra dúvidas, formula respostas, se defronta com seu não saber, se fortalece com suas possibilidades de vir a saber. Uma criança que tem cultura, história, memória, desejos, expectativas e experiências. Uma criança que dialoga dentro e fora da escola, pois o diálogo é um ato fundamental para a aprendizagem e para o ensino. Uma criança que encontra na escola um rico espaço de encontro com o outro e consigo mesma, de ampliação do conhecimento e de sua inscrição potente no mundo. Uma criança que tem nome, rosto, corpo, voz, gestos, vida.

Esta criança definitivamente não cabe numa linha, com 20 quesitos (dos quais só se preenchem os acertos, vale lembrar), de uma folha com outras tantas linhas, para outras crianças, de modo a se observar o resultado da "turma". Essa 
criança, e a turma à qual pertence, desaparece no documento, como resultado de sua reduzida presença no processo instituído, como efeito da simplificação e da uniformização exigidas pelos instrumentos utilizados e para as análises propostas. Porém, esta não é uma questão relevante para a dinâmica de avaliação efetivada, estruturada a partir da quantificação, como se pode observar no próprio documento: "o preenchimento da ficha permitirá a visualização do número de acertos de cada aluno e a média da turma." (INEP, 2011, p.14).

Segundo as orientações dos documentos oficiais relativos à Provinha Brasil, as respostas dos alunos podem ser interpretadas estabelecendo-se uma relação entre o número ou a média de acertos de um ou mais alunos e sua correspondência com níveis de desempenho ali descritos. Dessa forma, a quantidade de questões do teste que a criança consegue responder corretamente demonstra as habilidades por ela desenvolvidas, dentre aquelas previamente determinadas nos descritores presentes no documento que orienta o processo.

A partir dessa relação se pretende conhecer a aprendizagem infantil. A mensuração do desempenho na prova permite o enquadramento de cada estudante na escala previamente construída para orientar a formulação das questões da prova, sua correção e a interpretação dos resultados (nesta última etapa, a classificação das crianças é parte central). Aqui, se formula uma relação linear e causal entre quantidade e qualidade, por meio da associação entre uniformização e simplificação, que atua para reduzir a complexidade do sujeito, da aprendizagem, do ensino e da avaliação a um conjunto de indicadores, a partir do qual se infere a qualidade dos processos de aprendizagem e de ensino e se aplicam as orientações, também previamente elaboradas, para a continuidade do processo pedagógico, concebido exclusivamente sob uma perspectiva mecanicista e tecnicista. Se produz um documento para identificar um conjunto de "habilidades" predeterminadas, se verifica se elas estão presentes nas respostas dadas e todo o amplo universo de conhecimentos e desconhecimentos, impossível de ser percebido pelas 20 questões elaboradas, se torna, na medida em que invisível, inexistente.

Os processos sociais de construção de invisibilidade dos conhecimentos como forma de produzir a inexistência dos sujeitos estão solidamente discutidos (BHABHA, 1989; MIGNOLO, 2003; CASTRO-GÓMEZ, 2005, entre outros) e podem ser observados em diversos procedimentos escolares cotidianos e na relação que se estabelece entre o resultado nos testes de larga escala e as orientações oficiais para a continuidade do processo pedagógico.

A constatação da desvitalização do sujeito de quem se fala, me leva a indagar também para quem esse processo fala. 
Ressalto, inicialmente, a ausência de uma perspectiva dialógica no processo de avaliação externa instituído e na relação que se propõe com os docentes durante sua realização (desde sua aplicação até sua análise). Os documentos não falam com, mas são instrumentos que medeiam uma relação entre o sujeito que formula o teste e informa detalhada e exaustivamente o que e como deve ser feito, com qual finalidade e com qual interpretação e o/a professor/a que apenas executa as determinações.

Assim como os estudantes e a aprendizagem, os docentes e o ensino também são invisibilizados. Os documentos e os resultados do teste falam de um/a estudante idealizado e se dirigem a um docente do mesmo modo produzido. Um sujeito desterritorizalizado, amorfo, que pratica um ensino descontextualizado e esvaziado de sentido. Não importam as características da escola, o espaço em que se encontra, as relações intra e extraescolares que estabelece, $o$ percurso pessoal e profissional do/a professor/a, as condições em que trabalha ou a forma como conduz a prática pedagógica. A ficha de correção indica as habilidades de cada um dos/as alunos/as e a guia de correção e interpretação dos resultados dão as orientações sobre como o ensino deve se realizar de acordo com cada nível de desempenho aferido.

A ausência de diálogo e a inexistência de vínculos com cada experiência docente em sua singularidade expressam um documento formal que procura modelar as práticas e pouco fala com o/a professor/a envolvido com tantas possibilidades e dúvidas que se tecem em sua sala de aula, com os estudantes, com seus colegas, com as múltiplas questões que atravessam a vida escolar. Certamente um teste que produz um perfil desvitalizado dos estudantes e se faz acompanhar de prescrições que formatam, enquadram, classificam e normatizam pouco contribui com professores/as que diariamente se deparam com muitas dúvidas sobre as aprendizagens de seus alunos e alunas, que nem sempre conseguem que o ensino produza os efeitos esperados, que veem com grande preocupação o tempo passando e algumas das crianças se mostrando incapazes de aprender o que lhes está sendo ensinado e não consegue compreender o porquê dessa situação, que sabem que o que serve para um/a aluno/a não serve para o/a outro/a mesmo quando os resultados são similares.

A busca de resultados homogêneos, que informa os testes estandardizados, se faz acompanhar de orientações padronizadas que não respondem às diferentes e incessantes perguntas presentes na relação pedagógica. Os instrumentos, documentos e resultados nessa perspectiva produzidos falam para uma ação docente desvitalizada, mecânica, comprometida fundamentalmente com a obtenção de resultados válidos segundo o padrão vigente e fragilmente 
vinculada aos movimentos individuais e coletivos de produção e socialização de conhecimento.

A realização de testes estandardizados em larga escala, a construção de níveis de desempenho, a classificação dos estudantes nesses níveis e as proposições para a organização do ensino se articulam na efetivação de uma avaliação externa cujo objetivo é, pela medida do desempenho, fomentar práticas que elevem os índices obtidos aos patamares que expressem a qualidade almejada. Nesse sentido, todos os comportamentos, conhecimentos, habilidades ou resultados que não se enquadram no modelo estabelecido como válido são reconhecidos como desvios ${ }^{6}$.

A generalização, a descontextualização, a padronização e a fragmentação que caracterizam a avaliação realizada pela Provinha Brasil expressam uma qualidade sem sujeito, disforme, desencarnada, que subalterniza ao classificar, selecionar e distribuir os sujeitos diferentes por lugares desiguais. Uma qualidade que só se reconhece no mesmo, na homogeneidade, na reprodução e não abre espaço para a diferença, para o múltiplo e para o imprevisível.

Uma qualidade que se vincula a uma educação que nega a alteridade:

O outro da educação foi sempre um outro que devia ser anulado, apagado. Mas as atuais reformas pedagógicas parecem já não suportar o abandono, a distância, o descontrole. E se dirigem à captura maciça do outro para que a escola fique ainda mais satisfeita com sua missão de possuir tudo dentro de seu próprio ventre (SKLIAR, 2003, p. 27).

O modelo único em uma sociedade plural identifica (ou produz) muitos desvios, deficiências, incapacidades e mantém a avaliação como um importante elemento na construção de justificativas para o fracasso escolar (PATTO, 1991; COLLARES; MOYSÉS, 1996). Tal processo, historicamente presente na conformação da educação brasileira, não aporta informações que contribuam para uma reflexão profunda sobre a produção socioeconômica e cultural dos resultados obtidos e sobre a ação escolar, em suas múltiplas dimensões, como parte dessa produção. Os (maus) resultados são comumente explicados por relações que apontam o próprio sujeito que fracassa (ou suas condições de vida, a realidade de sua família, suas características inatas, etc) como responsável pelo fracasso. A individualização é parte da negação da alteridade.

6 Um dos objetivos da Provinha Brasil é prevenir o diagnóstico tardio das dificuldades de aprendizagem. Disponível em: <http://portal.inep.gov.br/web/provinha-brasil/objetivos>. Acesso em: 10 set. 2013. Tratei da abordagem classificatória do diagnóstico realizado pela Provinha Brasil em Esteban (2012). 


\section{ESCRITA, SABER E PODER - UMA RELAÇÃO INTENSA}

O cruzamento de dados macro e microestruturais expressa novas configurações para a escola, em especial a pública. Faz-se necessária uma perspectiva plural de qualidade, em que o diálogo, a diferença, a alteridade e a solidariedade articulem práticas escolares e processos avaliativos coerentes com os contextos em que se concretizam. Os diversos obstáculos a uma efetiva democratização da educação no Brasil assinalam a insuficiência do conceito de qualidade que vem animando as políticas públicas para a educação e muitas das práticas escolares cotidianas, que se apoia na compreensão da universalidade: do conhecimento, dos processos pedagógicos, do papel do professor, das características e da função do estudante e dos níveis, parâmetros, indicadores e procedimentos presentes no processo de avaliação externa.

A ênfase na homogeneidade não resulta do desconhecimento da existência da diferença, mas de uma abordagem da diferença que a aproxima da desigualdade. A observação, por exemplo, das orientações para a elaboração de questões para a Provinha Brasil expõe um discurso que reconhece a diferença, busca reduzi-la à diversidade ${ }^{7}$ e não deixa espaço para a alteridade.

Na organização do teste, a seleção do texto-base, sobre o qual será formulada a questão que permite medir a habilidade a que se refere o problema construído, requer alguns cuidados para atender a suas finalidades. No Guia de Elaboração de Itens - Provinha Brasil se explicita a preocupação com a seleção do texto e sua adequação à faixa etária a que se dirige. Como se pode observar no trecho a seguir:

Recomenda-se que o texto-base seja retirado das mais variadas fontes de circulação social: jornais, revistas, livros, cartazes informativos, sites, etc. Não é permitida a utilização de livros didáticos ou paradidáticos como fontes para a elaboração de itens ou seleção de textos- base. Além disso, a seleção do texto-base deve observar:

- escolha de gêneros textuais diversos;

- situações ou contextos comunicativos mais próximos à realidade;

- temáticas ligadas ao contexto infantil;

- se possível, considerar o cotidiano dos alunos (INEP, 2012, p. 34).

Ressaltar a importância do uso de vários suportes que permitem a circulação social da escrita e de diversos gêneros textuais, porém, não se relaciona à diferença de textos, suportes, gêneros e conteúdos que atravessa a escolarização como expressão da multiplicidade de culturas que os sujeitos partilham, tampouco ao

$\overline{7}$ Sobre a distinção entre diferença e diversidade, ver Bhabha (1989). 
reconhecimento da alteridade na produção/apropriação das linguagens. Apenas trata das variações presentes no modelo de língua escrita consagrado.

$\mathrm{Na}$ confecção dos itens importa, fundamentalmente, a funcionalidade de cada questão para medir a habilidade selecionada na Matriz de Referência ${ }^{8}$. Essa ênfase decorre de uma compreensão de que inicialmente o ensino deva privilegiar as convenções do código escrito, deixando para uma etapa posterior a inserção crianças na cultura escrita ${ }^{9}$. No teste, não importam as experiências que as crianças têm, inclusive com a leitura e com a escrita, pois a avaliação externa não se volta à compreensão de quem são as crianças, nem do que pensam, dizem, fazem ou como aprendem.

A "Provinha" mede, oferece dados para uma classificação e orienta a análise dos resultados. Contudo, ao utilizar os mesmos parâmetros e questões idênticas para medir habilidades iguais em sujeitos diferentes, o teste desconsidera a relação entre as diferentes experiências, aprendizagens e relações com os textos (em suas diversas modalidades). A dinâmica instaurada esvazia a relação entre construção de conhecimento e cultura, central na aquisição da linguagem, segundo os estudos da teoria sócio-histórica/cultural:

As pessoas não apenas possuem ferramentas mentais, elas também são possuídas por elas. Os meios culturais - a fala em particular - não são externos a nossas mentes, mas crescem dentro delas, criando, desse modo, uma "segunda natureza". O que Luria e Vygotsky pensavam é que o domínio dos meios culturais transformará nossas mentes: uma criança que dominou a ferramenta cultural da linguagem nunca será a mesma criança [...]. Assim, pessoas pertencentes a diferentes culturas literalmente pensariam de maneiras diferentes, e a diferença não estaria confinada ao conteúdo do pensamento como também à maneira de pensar (VAN DER VEER; VALSINER apud BAQUERO, 1998, p. 31).

A avaliação em larga escala, à qual se submetem todas as crianças matriculadas em escolas públicas brasileiras a partir do segundo ano do ensino fundamental, despreza as interações e mediações constituintes da aprendizagem em nome da intenção de medir, classificar, comparar e hierarquizar de modo considerado neutro e objetivo. As orientações para a elaboração dos itens da "Provinha" tomam a realidade, a infância, o cotidiano, o contexto e os alunos como modelos abstratos, construídos a partir de categorias consideradas uni-

8 Segundo o documento Guia de Elaboração de Itens (INEP, 2012), a Matriz de Referência delimita as habilidades que devem ser avaliadas e orienta a análise dos resultados do teste aplicado.

9 A Provinha Brasil trabalha com a distinção entre alfabetização e letramento. Geraldi (2013) apresenta uma perspectiva crítica a essa dissociação. 
versais. No âmbito do documento em discussão e da realização da avaliação externa nas escolas que temos acompanhado ${ }^{10}$, estas são apenas menções formais, pois o processo instituído pela avaliação externa não permite a explicitação/observação das diferenças em relação ao conteúdo do pensamento como também à maneira de pensar, uma vez que toda resposta diferente da predefinida representa um erro e a questão não é sequer marcada na Ficha de Correção da Provinha Brasil. Efetivamente, não há contexto, experiência, dinâmica social, diferença cultural, desigualdade econômica, interação, condicionantes geográficos ou processos históricos marcando de modo singular a pluralidade de modos de vida que se delineiam nas trajetórias de cada sujeito e se apresentam em seu processo de aprendizagem (muitas vezes traduzidos em diferentes resultados).

O documento estabelece como parâmetro "o universo da criança que está no $2^{\circ}$ ano de escolaridade". O que isso quer dizer? Em uma mesma sala de aula, vemos diariamente crianças no mesmo ano de escolaridade que vivem "universos" muito distintos. Não vejo possibilidade de se pensar um "universo comum" que oriente a escolha dos textos sobre os quais serão propostas as questões (comuns) do teste em um país com as proporções do Brasil. Não há possibilidade de se pensar em uma experiência comum de infância a todas as crianças submetidas ao exame, tampouco se pode considerar, em um teste único, o cotidiano dos estudantes.

A condução do pensamento sobre as relações entre os contextos comunicativos e a realidade (desconsiderada, portanto, sua multiplicidade), o contexto infantil e o cotidiano dos estudantes (ambos, mais uma vez no singular, ocultando sua singularidade) se referencia em reduções, o que expressa as relações de colonialidade - do ser, do saber e do poder, conforme Mignolo (2003) que se entrelaçam ao projeto moderno de escola de massas. O silenciamento e a produção da invisibilidade, características dessas interações sociais, se correlacionam à desqualificação da diferença e marcam os movimentos de subalternização que negam o outro como estratégia dos jogos de poder que permeiam a dinâmica social. Esse registro está igualmente presente no que se diz a respeito das crianças a partir dos seus desempenhos no teste e nas atividades escolares propostas para elas como desdobramento desses resultados.

Observa-se a coerência entre o fortalecimento de um discurso regulador sobre o processo de ensino/aprendizagem da escrita e a avaliação como

10 Nos 3 últimos anos, tenho acompanho diretamente, por meio das pesquisas que desenvolvo, 3 escolas e outras 10 envolvidas em trabalhos de monografia de conclusão de graduação, dissertações de mestrado e teses de doutorado que oriento, distribuídas por 5 municípios diferentes. 
mecanismo de classificação para o controle - traduzida como mensuração de desempenho -, ambos tomados como medidas necessárias à produção da (mal definida) qualidade da educação. As considerações de De Certeau (2002) sobre a prática escriturística aportam questões relevantes para a compreensão do que se coloca como tarefa à escola, nelas ressalto a compreensão dessa prática como mítica e moderna. Mítica por se configurar como um discurso fragmentado capaz de articular simbolicamente as práticas sociais heterogêneas, e moderna por se vincular ao progresso que, na perspectiva ocidental, se refere ao agir sobre a exterioridade, como execução da vontade para fabricar regras e modelos que levem à transformação do meio. Um progresso que atribui grande valor à escrita e retira valor da oralidade (ligada à origem, à tradição, às vozes), que passa a ser aquilo de que diferentes práticas, a escolar incluída, devem se diferenciar para se legitimarem.

Aprender a escrever define a iniciação por excelência em uma sociedade capitalista e conquistadora. É a sua prática iniciática fundamental. Foi preciso sentir os efeitos inquietantes de um tão prodigioso avanço para que suspeitássemos ser a formação da criança moderna uma prática escriturística (DE CERTEAU, 2002, p. 227).

Assim se define o ideal de formação da criança para inseri-la positivamente na sociedade moderna, letrada. A escritura, como prática concreta, demanda um lugar de produção do sujeito, um conjunto de operações articuladas que formam um sistema de significados e uma ação social capaz de atuar sobre a exterioridade. "Ela estoca aquilo que vai selecionando e se dá os meios de uma expansão. Combinando o poder de acumular o passado e o de conformar a seus modelos a alteridade do universo, é capitalista e conquistadora." (DE CERTEAU, 2002, p. 226. Em itálico no original).

O exame como mecanismo de controle e regulação dos processos e dos resultados está em sintonia com essa prática escriturística que condiciona a inscrição dos sujeitos na dinâmica social hegemônica. Destaca-se seu papel na conformação dos sujeitos - estudantes e professores/as - aos modelos desde o início do processo de ensino-aprendizagem da escrita, na escola, quando produz resultados que se tornam um indicador dos diferentes lugares sociais que os sujeitos podem ocupar nessa sociedade em que a escrita representa um divisor de águas.

O posicionamento dos sujeitos na hierarquia social - que guarda lugares desiguais para sujeitos diferentes - não é efeito exclusivamente da ação esco- 
lar, obviamente. É parte de um intrincado conjunto de relações que envolve aspectos sociais, econômicos, históricos e culturais, que se inicia muito antes de a criança entrar na escola e se produz numa tensa dinâmica que contém múltiplas possibilidade para manter e/ou transformar o lugar ocupado por cada indivíduo. O desempenho nos exames é parte desse processo e mesmo não havendo uma correspondência unívoca entre origem social do estudante, o resultado auferido e a posterior condição social do sujeito, são fortes as correlações entre esses termos.

$\mathrm{Na}$ avaliação externa, a construção do teste, a mensuração do desempenho e a interpretação de seus resultados se pautam em procedimentos considerados neutros e objetivos, condição necessária para que seus resultados se apresentem como verdade. Consoante a essa elaboração, os documentos que compõem o "kit Provinha Brasil", com a função de orientar a aplicação do teste, a análise dos resultados e o encaminhamento pedagógico, desconsideram as dimensões sócio-culturais dos resultados obtidos, da formulação das questões (incluindo os parâmetros para sua análise) e das práticas curriculares, e reduzem o pedagógico a técnica.

Os cinco níveis de desempenho dos estudantes na Provinha Brasil expressam o grau de domínio de habilidades necessárias à apropriação e uso da escrita. Tal classificação se torna possível somente como parte de uma operação em que se uniformizam condutas, tendo como referência um universo reduzido de comportamentos esperados, a partir do desprezo da alteridade, traduzido em uma grande simplificação da aprendizagem e das distintas formas de sua expressão. Deste modo, a classificação decorrente do processo é aceita como uma verdade que expõe objetivamente o valor de cada sujeito, o que compõe a trajetória em que se define seu lugar social, visto como consequência de sua capacidade, em parte inferida a partir da mensuração do desempenho referido a um modelo uniforme de aprendizagem.

A classificação verdadeira se articula à seleção justa. Essa relação, fundamental na articulação da noção de qualidade presente na dinâmica social hegemônica, encobre o reconhecimento da justiça dos processos de exclusão nela implícitos e oculta sua face antidemocrática. A exclusão escolar é um longo processo que não nasce na escola, embora se consolide durante alguns anos da escolarização obrigatória, por meio de múltiplos, e nem sempre visíveis, movimentos de negação da alteridade como parte das tantas negações que os processos de subalternização historicamente impõem, em especial, aos sujeitos das classes populares. Nesse sentido, os desempenhos insuficientes nos anos iniciais frequentemente funcionam não tanto como um diagnóstico para uma 
intervenção pedagógica que leve à aprendizagem, mas como um prognóstico de futuros resultados insatisfatórios ${ }^{11}$. A demarcação social da classificação produzida e a distribuição desigual dos resultados alcançados ${ }^{12}$ mostram ser oportuno recorrer mais uma vez ao pensamento de De Certeau:

A ideologia dominante se muda em técnica, tendo por programa essencial fazer uma linguagem e não mais lê-la. [...] Isso implica um afastamento do corpo vivido (tradicional e individual) e, portanto, também de tudo aquilo que, no povo, continua ligado à terra, ao lugar, à oralidade ou às tarefas não verbais. O domínio da linguagem garante e isola um novo poder. [...] Esse poder, essencialmente escriturístico [...] define o código da promoção sócio-econômica e domina, controla ou seleciona segundo suas normas todos aqueles que não possuem esse domínio da linguagem. A escritura se torna um princípio de hierarquização social [...]. Ela funciona como uma lei de uma educação organizada pelas classes dominantes que pode fazer da linguagem (retórica ou matemática) o seu instrumento de produção (2002, p. 230).

O sistema de avaliação externa em vigor se configura no âmbito dessa economia escriturística como um significativo artefato do processo de hierarquização social. A negação da diferença é uma das estratégias da produção justificada da desigualdade. Porém, a presença crescente das classes populares na escola expõe as fraturas características da educação escolar e produz constantes confrontos entre diferença e desigualdade que não podem ser apaziguados com o apelo à diversidade ${ }^{13}$.

Essa tensão demanda o questionamento da manutenção das classes populares em posição de subalternidade e a ambivalência das práticas escolares que simultaneamente se vinculam aos processos de emancipação e negam a obtenção do conhecimento a muitos. A democratização do acesso ao conhecimento não pode se dar exclusivamente via escola. Mas a escola é necessária e o conhecimento é condição para a efetiva libertação. A negação do direito de apropriação da escrita por todos, mesmo diante de políticas públicas que se propõem a incrementar a qualidade da educação nacional, não exige apenas a reformulação de aspectos da prática pedagógica, pois requer a indagação do projeto de sociedade em curso e da concepção de democracia que o sustenta.

11 Estudos como A produção do fracasso escolar (PATTO, 1991); A institucionalização invisível (MOYSÉS, 2001) e A escola dos que passam sem saber (ANDRADE, 2003) dão interessante contribuição a essa discussão.

12 A esse respeito, retomar a nota $\mathrm{n}^{\circ} 5$, onde se apresentam indicadores educacionais.

13 Sobre a relação entre diferença, diversidade e desigualdade ver Bhabha (1989) e Esteban (2006). 


\section{PROCEDIMENTOS FORMATADOS E SUJEITOS MULTIFORMES}

O cotidiano escolar produz muitas questões sobre a avaliação dos estudantes, tanto no que se refere a como realizá-la quanto sobre suas relações com as aprendizagens e com os processos de ensino, sua configuração sociocultural, sua implicação no delineamento de uma educação de qualidade, entre outras. A reflexão até aqui proposta percebe, no processo de avaliação externa instituído, pouca contribuição para a elaboração dessas questões e para a promoção de uma educação de qualidade socialmente referenciada, que envolve a qualidade científica, a pedagógica e a democrática. É claramente insuficiente uma avaliação, da aprendizagem ou da qualidade das escolas, reduzida a uma prática de exame, simplificada como mensuração de desempenho por meio de testes estandardizados e parâmetros uniformes.

Considerando as questões do cotidiano escolar, em especial da sala de aula, local onde a dinâmica pedagógica ganha intensidade pelas interações entre professores/as e estudantes, desvinculo a qualidade da educação da elevação nos índices de desempenho de estudantes, de escolas, de municípios e do país. $\mathrm{Na}$ verdade, me preocupa a associação entre conquista da qualidade e a elevação de índices de desempenho, com profunda desconsideração dos processos e conteúdos da aprendizagem, uma vez que aprendizagem e desempenho não se equivalem. Penso ser insatisfatório um currículo baseado na transmissão/assimilação de fragmentos de conteúdos, descontextualizados, sem referências nas experiências dos estudantes, de suas famílias, de seus grupos de pertencimento e em sua inserção sociocultural. O currículo, assim pensado, se configura a partir de um mínimo que deve ser comum a todos, portanto, uma proposta reduzida de conhecimento e redutora da potência da aprendizagem e do ensino, que desqualifica culturas locais e saberes populares, sem demonstrar uma efetiva preocupação com a ampliação cultural dos estudantes.

A relação entre a avaliação da educação e o currículo é tratada por Bonamino e Souza em artigo em que:

Discutem-se os riscos de as provas padronizadas, com avaliações que referenciam políticas de responsabilização envolvendo consequências fracas e fortes, exacerbarem a preocupação de diretores e professores com a preparação para os testes e para as atividades por estes abordadas, levando a um estreitamento do currículo escolar (2012, p. 373).

A preocupação assinalada pelas autoras se intensifica quando se desloca o foco para as práticas escolares cotidianas. O exame determina o conteúdo 
e também o modo como será verificado, portanto, atua na formatação das atividades escolares, no direcionamento do olhar para e da escuta de o que produzem as crianças e na elaboração das interpretações do que é percebido como aprendizagem naquilo que os estudantes demonstram a partir do que lhes é proposto e do que deles se espera. A redução marca a intenção de unificação de processos pedagógicos - envolvendo o o quê e o como ensinar/aprender em uma sociedade constituída por grandes diferenças sociais, econômicas e culturais e por intensa hibridização.

Há um crescente distanciamento dos parâmetros uniformes que orientam a avaliação externa e a dinâmica de avaliação necessária à interação com a produção infantil, no processo de alfabetização, que não está restrita ao treinamento e à verificação dos procedimentos de codificação e decodificação.

O texto de Gustavo (estudante do $2^{\circ}$ ano do ensino fundamental), cujo título é A Liga do Mal, mostra a inadequação de uma avaliação articulada por parâmetros uniformes e classificação dos estudantes segundo seus resultados.

\section{Figura 2}

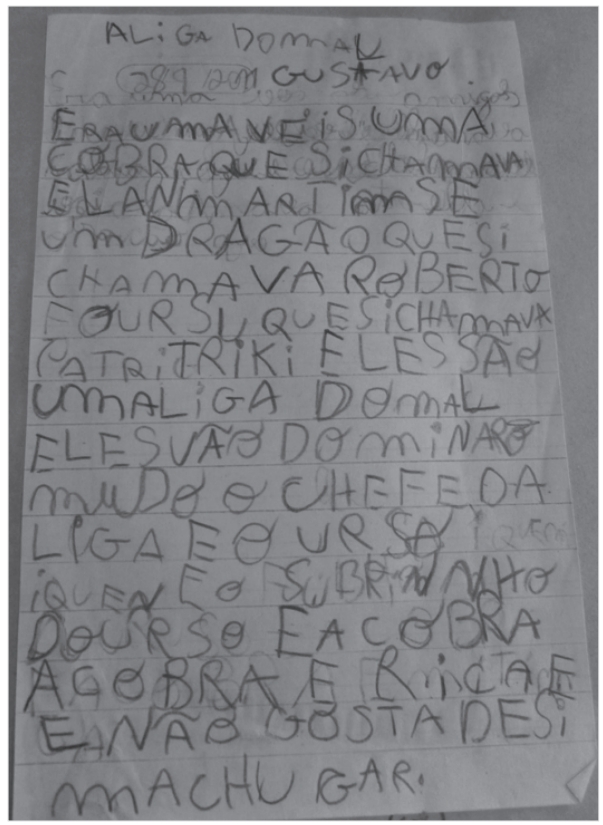

Era uma vez uma cobra que se chamava Elan Martins e um dragão que se chamava Roberto e o urso que se chamava Patriki Eles são uma liga do mal Eles vão dominar o mundo o chefe da liga é o urso e quem é o sobrinho do urso é a cobra A cobra é rica e não gosta de se machucar. 
A leitura desse texto nos permite fazer várias observações sobre seus conhecimentos a respeito da escrita, os usos que dela faz, os desconhecimentos que revela e os modos como utiliza o que já sabe para ultrapassar o que ainda não sabe, o tema escolhido, as relações que estabelece com suas experiências cotidianas e suas observações sobre a vida.

Diante de um tema que não corresponde à idealização sobre o contexto infantil e seus muitos erros, indago qual poderia ser a representação deste menino numa ficha de avaliação semelhante à proposta pela Provinha Brasil e qual nível alcançaria. Como ele responderia às questões do teste na avaliação externa? Sobretudo, entendo ser relevante perguntar como os parâmetros uniformes de classificação dos resultados e indicação de procedimentos pedagógicos podem oferecer informações significativas para que a professora de Gustavo avalie sua aprendizagem, a adequação dos procedimentos de ensino utilizados às demandas do menino e use a avaliação como auxiliar para a redefinição dos procedimentos que se mostrem insuficientes. Se observamos, além do que está implícito nas orientações para a elaboração de questões, a matriz de referência da Provinha Brasil e as questões efetivamente apresentadas nos testes até agora realizados, torna-se ainda mais visível o afastamento entre o proposto e esperado e a produção textual da criança, como parte de sua aprendizagem.

Outras produções de estudantes de séries iniciais reafirmam a inadequação do modelo de avaliação proposto, para a ampliação do conhecimento no processo aprendizagem-ensino. Uma avaliação que nega e invisibiliza a diferença não é compatível com um processo atravessado por múltiplas diferenças, como é a aprendizagem e, especialmente, a aprendizagem da escrita. Diante de uma mesma pergunta sempre são possíveis diferentes interpretações e diferentes respostas, o que não é aceito no modelo que classifica as crianças segundo seus acertos em um teste com questões objetivas.

Trago mais duas atividades, feitas por crianças diferentes a partir da mesma proposta da professora: que elas (em dezembro de 2009) escrevessem seus "desejos para 2010". Marcos e Allison fazem trabalhos muito diferentes.

As diferenças nas habilidades de escrita são evidentes e levariam os dois meninos a pontos desiguais na classificação utilizada, pois, objetivamente, o primeiro tem uma escrita ilegível e o segundo, embora escreva com erros, produz um texto legível. Entretanto, para mim, o que se apresenta como mais significativo nesses textos é a diferença em seus conteúdos, as leituras de mundo que as crianças fazem e as leituras que nos permitem fazer das experiências dessas crianças. Mais importante do que sua classificação pela quantidade de habilidades que (não) apresentam é a compreensão de seus percursos e o papel que a escola neles pode desempenhar. 
Figura 3

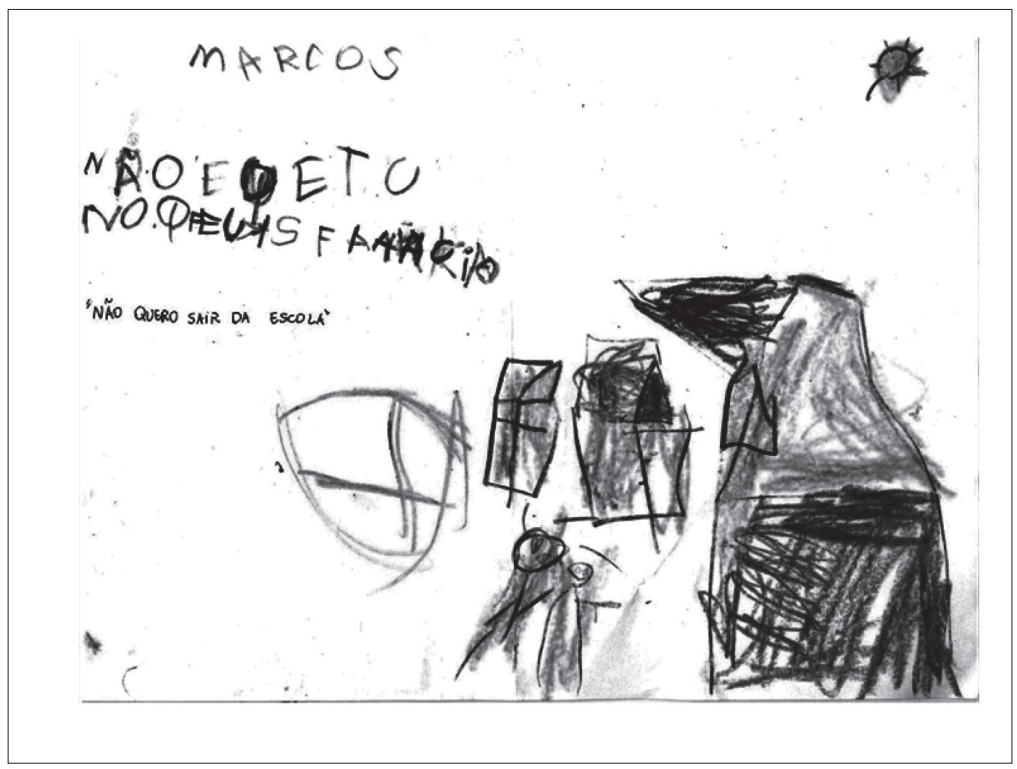

Figura 4

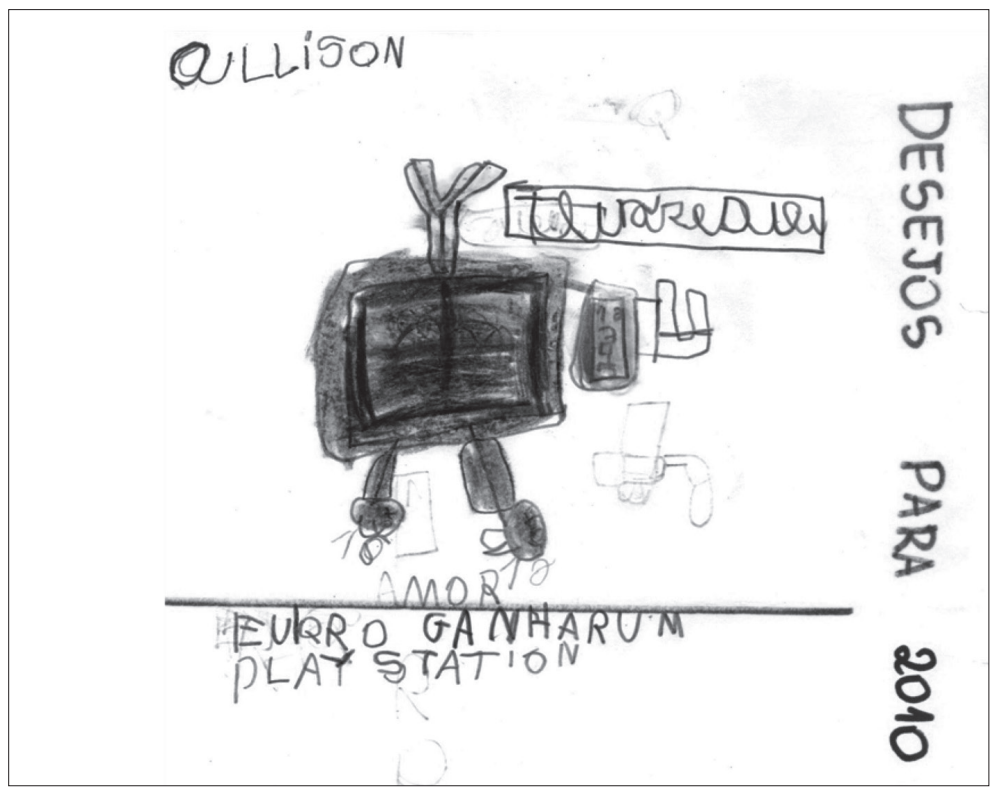


O desejo do primeiro menino para o ano vindouro é não sair da escola, o do segundo é ganhar um brinquedo bastante caro e valorizado entre as crianças. É o primeiro que me produz impacto: ele vê sua continuidade na escola em risco? Por quê? Que relações podem haver entre sua aprendizagem considerada insuficiente para seu tempo de escolarização e seu temor de sair da escola?

Essas perguntas se abrem a muitas outras, referidas mais diretamente ao trabalho pedagógico do qual ele participou e às possibilidades que a professora teve para perceber o processo que ele estava desenvolvendo. Uma avaliação que verifica erros e acertos a partir de questões e parâmetros predefinidos que resulta em um quantitativo que permite a classificação do estudante em categorias predeterminadas certamente tem pouco a dizer sobre um menino que parece ter se apropriado tão fragilmente da escrita. Essa avaliação desconsidera, inclusive, a aprendizagem que Marcos já fez de que a escrita é instrumento de compreensão do mundo para nele intervir.

O não reconhecimento das habilidades elencadas nos documentos que orientam a prática curricular ${ }^{14}$ frequentemente se traduz como não aprendizagem por parte da criança. Como se classifica a criança de acordo com esse reconhecimento, aquela que contabiliza poucas habilidades é posta nos níveis mais baixos e seu resultado é visto como indicador de dificuldade de aprendizagem ${ }^{15}$. Assim, se constitui e consolida a relação entre diferença na aprendizagem e dificuldade de aprendizagem, esta comumente interpretada por um viés patologizante. $\mathrm{Na}$ análise proposta em documentos oficiais não se levanta a hipótese de que a diferença de respostas decorra das diferenças na interpretação - tanto da pergunta quanto das repostas apresentadas como possíveis em um teste objetivo - como parte das diferentes experiências e culturas partilhadas pelos estudantes. Esta segunda opção não expressaria um problema de aprendizagem, mas formularia problemas para as práticas curriculares.

Há uma farta produção no campo dos estudos curriculares indicando a complexidade do currículo, inclusive por estar atravessado pela singularidade das trajetórias, que lhe imprimem características próprias e demandam sua contextualização. Um exemplo bastante reconhecido é o papel significativo desempenhado pelo currículo oculto nos processos e resultados escolares e

14 A avaliação da aprendizagem no cotidiano escolar pode ser orientada por documentos específicos produzidos pelas Secretarias de Educação. Em geral possuem correspondência com as matrizes de referência dos exames nacionais, mas podem apresentar algumas especificidades.

15 Segundo o Guia de Correção e Interpretação de resultados da Provinha Brasil (INEP, 2011) a Provinha Brasil foi instituída com a perspectiva de melhorar os níveis de letramento, tendo como um de seus objetivos informar às redes de ensino sobre a qualidade da alfabetização e evitar o diagnóstico tardio das dificuldades de aprendizagem. Tratei da abordagem classificatória do diagnóstico realizado pela Provinha Brasil em Esteban (2012). 
sua atuação na produção de diferenças entre o currículo prescrito e os muitos currículos que efetivamente se realizam nas escolas, em relação com as múltiplas interações cotidianas.

Esse debate perde importância nas orientações, que se estruturam segundo a quantidade de acertos das crianças, endereçadas aos professores e professoras:

As respostas dos alunos podem ser interpretadas estabelecendo-se uma relação entre o número ou a média de acertos de um ou mais alunos e sua correspondência com níveis de desempenho descritos para a Provinha Brasil. Dessa forma, quando a criança consegue responder corretamente a um quantitativo de questões do teste, ela demonstra ter desenvolvido determinadas habilidades (INEP, 2011, p. 14).

A descrição de cada um dos níveis se complementa com considerações e sugestões de trabalho baseadas em uma análise dos resultados sustentada por interpretações uniformes e descontextualizadas. Conectam-se ao modelo de estudante previsto para cada nível e não ao processo de aprendizagem e às características do ensino realizados, correspondem a uma simplificação, já que tratam apenas da transmissão de informações e do treinamento de habilidades, ignorando as complexas relações intersubjetivas, intertextuais e intrapsíquicas que percorrem a dinâmica escolar. Ainda que se apresentem como sugestões, seu caráter prescritivo vem à tona quando são associadas a políticas de responsabilização forte, aquelas que, segundo Bonamino e Sousa (2012), produzem consequências materiais ou simbólicas para os sujeitos escolares. A necessidade de que todos alcancem níveis comuns em tempos idênticos ${ }^{16}$ expõe um modelo de avaliação que tende a atuar também na redução da autonomia docente.

Evidencia-se uma qualidade ancorada na meritocracia em que se admitem, ou melhor, se esperam, níveis desiguais para sujeitos diferentes. Uma qualidade que, no lugar de promover, impede, articulada por uma perspectiva excludente, que fortalece a avaliação da aprendizagem classificatória e seletiva - amplamente criticada no âmbito desse campo de estudos -, inibe práticas participativas que articulem os diferentes segmentos que compõem a escola e estimula práticas pedagógicas mecanicistas e reducionistas. Não se coaduna, portanto, com uma qualidade (talvez seja mais adequado, qualidades) socialmente referenciada, em que estão presentes o científico, o pedagógico e o democrático, já que diminui o potencial reflexivo, dialógico, participativo e emancipatório da escola e do conhecimento.

16 Em documentos relativo a Provinha Brasil, há recomendação no sentido de que ao término do segundo ano de escolaridade, todas as crianças atinjam, pelo menos, os níveis 3 ou 4 e de que se observe especialmente o trabalho com as crianças que neste mesmo período estejam nos níveis 1 e 2 (INEP, 2011, p. 19). 
A avaliação é um processo indispensável à conquista das qualidades almejadas e à composição cotidiana da prática pedagógica. Na perspectiva à qual me filio, sua potência está em sua capacidade para mobilizar a reflexão partilhada sobre os percursos, individuais e coletivos, realizados na relação aprendizagem-ensino, para compreendê-la e planejar a continuidade do trabalho de modo ampliar permanentemente os conhecimentos de todos os envolvidos no processo, com a participação de todos. Sua capacidade reflexiva e seu potencial para trazer para o cotidiano escolar múltiplas questões, incluindo as significativas para a comunidade em que a escola se insere, a conectam ao currículo na elaboração de práticas que estimulem permanentemente a ampliação, o aprofundamento e o questionamento do conhecimento pela possibilidade de articulá-lo ao imprevisto, ao inesperado, ao novo, ao outro.

A discussão sobre a qualidade da educação, seus sentidos e suas práticas, precisa considerar a pluralidade de concepções, projetos e expectativas existentes e a tensão presente na tomada de decisões. A força do projeto de educação em curso, do qual o conceito de qualidade e o processo de avaliação em larga escala são parte, não pode ser ignorada, mas também não pode servir para apagar a existência de uma disputa em torno de seus sentidos. O projeto hegemônico não é o único e certamente não atende as demandas de parcelas significativas da sociedade brasileira, o que requer outras propostas. Estamos comprometidos com a qualidade da educação pública, discordamos do projeto implementado e vemos outros percursos, uma vez que tomamos como referência outra concepção de qualidade, que nos remete à colaboração, à solidariedade, à crítica e ao coletivo e se sustenta no reconhecimento da positividade da diferença.

Por isso, estamos em luta, disputando sentidos e nos colocando frontalmente contra os discursos e processos que negam valor à diferença na relação ensino-aprendizagem e trazem a diferença cultural como meio para fragmentar o conhecimento, inferiorizar a muitos sujeitos e saberes, enfatizar o individualismo, desqualificar a alteridade e justificar a desigualdade.

Como historicamente nos mostra o movimento de professores - incluindo este momento em que professores de redes públicas expressam claramente sua discordância com a meritocracia -, a luta por uma escola pública, gratuita, laica e de qualidade é dura, mas necessária e, mesmo diante da violência (material e simbólica), é possível. 


\section{REFERÊNCIA}

ANDRADE, Dília Maria Glória. A escola dos que passam sem saber: a prática da não retenção escolar na narrativa de alunos e familiares. Revista Brasileira de Educação, Rio de Janeiro, n. 22, p. 61-77, jan-abr, 2003.

BAQUERO, Ricardo. Vygotsky e a aprendizagem escolar. Porto Alegre: Artes Médicas, 1998.

BHABHA, Homi. O local da cultura. Belo Horizonte: UFMG, 1989.

BONAMINO, Alicia; SOUSA, Sandra Záquia. Três gerações de avaliação da educação básica no Brasil: interfaces com o currículo da/na escola. Educação e Pesquisa, São Paulo, v. 38, n. 2, p. 373-388, abr.jun, 2012.

CASTRO-GÓMEZ, Santiago. Ciencias sociales, violencia epistémica y el problema de la "invención del otro". In: LANDER, Edgardo (Org.). La colonialidad del saber: eurocentrismo y ciencias sociales. Perspectivas latinoamericanas. Buenos Aires: CLACSO, 2005. p. 145-162.

COLLARES, Cecília; MOYSÉS, Maria Aparecida. Preconceitos no cotidiano escolar: ensino e medicalização. São Paulo: Cortez, 1996.

DE CERTEAU, Michel. A invenção do cotidiano. Artes de fazer. Petrópolis: Vozes, 2002.

DÍAZ BARRIGA, Ángel. Uma polêmica em relação ao exame. In:

ESTEBAN, Maria Teresa (Org.). Avaliação: uma prática em busca de novos sentidos. Rio de Janeiro: DP\&A, 1999. p. 51-82.

ESTEBAN, Maria Teresa. Considerações sobre a política de avaliação da alfabetização. Revista Brasileira de Educação, Rio de Janeiro, v. 17, n. 51, p. 573-743, set-dez, 2012.

. Sala de Aula: dos lugares fixos aos entrelugares fluidos. Revista Portuguesa de Educação, Lisboa, v.19, n. 2, p. 7-20, 2006.

GERALDI, João Wanderley. Alfabetização e letramento: perguntas de um alfabetizado que lê. Disponível em: <www.moodle.ufba.br/mod/resource/ view>. Acesso em: 22 de set. 2013. 
IBGE - INSTITUTO BRASILEIRO DE GEOGRAFIA E ESTATÍSTICA. Pesquisa Nacional por Amostra de Domicílios (PNAD) 2012. Rio de Janeiro: IBGE, 2013. Disponível em < http://www.ibge.gov.br > . Acesso em: 10 set. 2013.

. Síntese de indicadores sociais: uma análise das condições de vida da população brasileira. Rio de Janeiro: IBGE, 2010.

INEP - INSTITUTO NACIONAL DE ESTUDOS E PESQUISAS EDUCACIONAIS. Guia de elaboração de itens - Provinha Brasil . Brasília. 2012. Disponível em: $<$ http://portal.inep.gov.br/web/provinhabrasil/provinha-brasil $>$. Acesso em: 22

set. 2013.

. Guia de correção e interpretação de resultados da Provinha

Brasil - Leitura - Teste 2. Brasília. 2011. Disponível em: $<$ http://portal.inep. gov.br/web/provinha-brasil/kit-teste >. Acesso em: 22 set. 2013.

MIGNOLO, Walter. Histórias locais projetos globais. Belo Horizonte: UFMG, 2003.

MOYSES, Maria Aparecida. A institucionalização invisível. Crianças que não aprendem- na- escola. Campinas: Mercado de Letras, 2001.

PATTO, Maria Helena de Souza. A produção do fracasso escolar. São Paulo: T.A.Queiroz, 1991.

SKLIAR, Carlos. Pedagogia (improvável) da diferença. E se o outro não estivesse aí? Rio de Janeiro: DP\&A, 2003. 